\title{
Effective Use of Peer-Feedback in Developing Academic Writing Skills of Undergraduate Students
}

\author{
Yi Yi Mon \\ Department of Languages \\ The University of Computer Studies, Mandalay, Myanmar \\ Subhan Zein \\ The University of Queensland, Australia \\ ORCID ID: 0000-0003-3787-3211
}

\begin{abstract}
This paper investigates an effective way to develop academic writing skills of 4th year students of at a university in Myanmar in using peer reviewing and a guided peer-feedback process. A comparison was made to determine the effectiveness between the instructor feedback and peer feedback implementation based on the students' revision work. Twenty students' papers became the focus of four different types of written feedback: Error Identification, Error Correction, Descriptive Comment and Critical Comment. Data on the number of feedback on the students' final assignments and final paper were collected to study the feedback implementation rate and types of feedback students incorporated into their revision work. It was found that peer feedback effect had greater on error identification than instructor feedback. This is despite a significantly higher revision rate of instructor feedback on error correction. This study outlines some implications for second language writing on providing effective peer feedback in Myanmar and other contexts in the ASEAN region. Keywords: peer feedback, types of written feedback, written corrective feedback, teacher feedback
\end{abstract}

In second language (L2) writing, written corrective feedback otherwise known as grammar correction (e.g. Truscott, 1996, 1999) or written error correction, has been a heated topic of interest in applied linguistics in the past decade. Different types of feedback such as direct and explicit written feedback; student-teacher individual conferences; direct, explicit written feedback and peer-feedback have been proven useful for varying degree of outcomes (e.g. Bitchener, Young \& Cameron, 2005; Lundstrom \& Baker, 2009; Storch, 2004). The use of peer feedback in particular has been recommended by many researchers due its social, cognitive and affective benefits (Lundstrom \& Baker, 2009; Min, 2008; Storch, 2004) and peer

Language Education in Asia, 2017, 8(2), 176-191. http://dx.doi.org/10.5746/LEiA/17/V8/I2/A04/Mon_Zein 
assessment has been increasingly used in higher education with the least possible time invested by the instructor (Landry, Jacobs \& Newton, 2014).

Despite the many studies on peer feedback in improvinsg the quality of students' writing (e.g. Cho, Schunn \& Wilson, 2006; Gielen, Tops, Dochy, Onghena \& Smeets, 2010; Topping, 1998; Van Gennip, Segers \& Tillema, 2010), studies on the comparison between the efficacy of peer feedback and the types of feedback given in relation to teacher feedback are rare. This is especially evident in the context of undergraduate programs with a large number of students where provision of individual feedback from teachers is very unlikely. To date, there has only been a study by Yang, Badger \& Yu (2006) that compares the efficacy of peer-feedback and teacher feedback in an examination focused program at a university in China with various administrative constraints resulting from a large number of students. With a large university in Myanmar being the research context, the study reported in this paper investigates the effect of peer feedback and that of instructor feedback to identify which type of feedback that undergraduate students implemented the most.

The presentation of the paper is as follows. First, it outlines the theoretical overview providing the rationale for the conduct of this study. Second, it elaborates on the methodological tenets employed to collect and analyze data in this study. Third, the findings of the study are presented in the subsequent section. Afterwards, the findings are discussed in light of relevant literature. Some concluding remarks are provided at the end of the paper.

\section{Literature Review}

An upsurge in research on peer feedback in L2 writing has occurred in the past two decades. Jacobs et al. (1998), argue that peer feedback is perceived by students in ESL writing class as one type of valuable feedback despite its efficacy and usefulness being secondary to teacher feedback. Jacobs et al.'s (1998) study, however, has been under scrutiny. Zhang (1999) questions the methodological validity in Jacobs et al.'s (1998) study) and emphasizes the need to reexamine assumptions about the ESL writing process in order to better address the affective disadvantage of peer feedback relative to teacher feedback in the ESL writing class. Yang, Badger \& Yu (2006) reveal that although students in their study were more likely to adopt teacher feedback in the improvement of the writing performance, peer-feedback was essential for the provision of a higher degree of student autonomy, even in a highly-authoritative learning context such as China. Similarly, Tsui and Ng's (2000) study also demonstrates the preference of students in receiving teacher feedback to obtaining peer feedback, but there was a positive contribution of peer comments in the interview in terms of four specific roles: a sense of audience, raising learners' awareness, collaborative learning and ownership of the text. A study by Gielen et al., (2010) further demonstrates the cognitive advantages drawn from peer feedback as it is deemed conducive to the enhancement of students' ability to grasp the goals and criteria of feedback given its use of plain language. Peer feedback has also been proven useful in increasing insights into writing and revision processes (Peterson, 2003) and raising students' awareness of audience (Tsui \& Ng, 2000), both prompting them to expend more considerable effort on their writing. 
Research has consistently indicated that increased writing skills are feasible due to the quality feedback received from many different peers rather than instructor alone (Gielen et al., 2010; Richer, 1992; Topping, 1998; Van Gennip et al., 2010;). The benefits gained from peer feedback appear to have stemmed from the undeniable benefits of peer feedback (Zhang, 1999) when it is used judiciously as part of a combination of feedback strategies (Jacobs et al., 1998). Bitchener, Young \& Cameron (2005) found that the use of different feedback strategies such as teacher feedback and peer feedback has positive effect on accuracy performance. They recommended classroom L2 writing teachers to regularly provide their learners with both oral feedback as well as written feedback on the types of linguistic errors that are "treatable". Various studies have suggested that the benefits gained from peer feedback are not only due to the timeliness of the feedback as supposed to teacher feedback (Ngar-Fun \& Carless, 2006) but also its supportive nature (Landry, Jacobs \& Newton, 2014) occurring during the collaborative process in which learners work together with their peers and develop insight into their peers' ideas and opinions (Van Gennip et al., 2010). There is also the affective advantage inherently attached to peer feedback that somehow could make peer feedback far more appealing than teacher feedback, although this is largely dependent upon certain learner characteristics (Zhang, 1995; 1999). When combined with pair composition, for example, pair processing of feedback provides learners with various cognitive processes that are conducive to language learning (Wigglesworth \& Storch, 2009). According to Wigglesworth \& Storch (2009), deliberation of feedback allows learners to draw their attention to the knowledge gap in their writing as well as their explicit knowledge of language, previously learned language rules and linguistic intuitions. For this reason, Rust, Price \& O'Donovan (2003) suggest that students should be provided with opportunities to participate more actively in formative peer feedback.

Although there are many benefits to peer feedback in the EFL context, peer feedback implementation may be challenging to the students. One important finding about peer feedback implementation appears in Nelson \& Schunn (2009) who examined the correlations between the feedback features, levels of mediating variables, and implementation rates. Nelson \& Schunn (2009) discovered that understanding was the only significant mediator of implementation, which means students are likely to revise their writing only if they understand the feedback and know how to give one.

By way of implication, the benefits of peer feedback are unlikely without adequate training on the part of the students (Min, 2016). In order to develop an effective peer-reviewing activity, Min (2006) recommended giving peer reviewing training which should be a combination of inclass and individual conferencing with the instructor. Various studies on the types of intervention that teachers can provide to train students to conduct peer feedback have been reported, including in traditional face-to-face (e.gs. Hu, 2005; Lam, 2010) and online situations (Yang \& Meng, 2013). Peers' increased awareness of the effectiveness of their comments (Lam, 2010), enhanced ability to focus on high-order issues (Min, 2005) and improved types of revision and quality (Liou \& Peng, 2009) have all been reported as the positive impacts resulting from direct interventions on peer feedback. In Min's (2006) study, students' writing quality and revision types were significantly higher than before the peer review training. Lundstrom \& Baker (2009) also found that the reviewers who only focused on their peer's 
writing had more benefits in their own writing over the course of the semester than did the receivers, who focused solely on using peer feedback.

Despite the reported success in previous literature on peer feedback, scant knowledge is available about the effect of peer feedback and the types of feedback given in relation to teacher feedback. This is particularly relevant in the cases of various types of feedback given by students to their peers, including error identification, error correction, descriptive comment and critical comment. Conducting study within this line of inquiry is particularly important in the context of large writing classes at undergraduate level in Myanmar in which the class size of 75 to 80 students may not allow the instructor to give effective individual feedback on a regular basis during the course. The growing concern among English language instructor at a university in Myanmar where the study took place was that whether students would be able to implement the feedback appropriately in the revision of their writing tasks given their sole familiarity with teacher feedback. This gave the impetus for this study.

Therefore, this study investigated the effect of teacher (instructor) feedback and peer feedback on students' revisions and the types of feedback that most students implemented in their subsequent writing tasks. The student attempted to answer the following research questions:

1. What is the effect of instructor feedback and peer feedback on students' revision papers?

2. What type of peer feedback do most student writers incorporate into their writing?

\section{Methodology}

In this study, sampling strategy was used to investigate the effect of peer feedback and peer feedback types (error identification, error correction, descriptive comment and critical comment). The number of in-text feedback and overall feedback given by the instructor and peers (reviewer 1, reviewer 2 and reviewer 3 ) on 20 randomly selected papers were counted. An analysis of the data on instructor-feedback and peer-feedback on these 20 papers was done. The effect of peer feedback on students' writing ability was assessed by the number of in-text feedback on final assignment which had been incorporated into writing after peer feedback. Then, this was compared with the rate of students' revision work after instructor feedback on the first drafts. The research was done on students' feedback implementation rate over final assignment and final paper by studying the number of evidences for changes in writing (grammar, punctuation, format, vocabulary) which was compared with the previous writings on the first drafts and final assignments. The data on the number of comments on final assignments were also collected to investigate on which assessment categories students gave peer feedback.

\section{Participants and Procedures}

Fourth year students of the University of Computer Studies, Mandalay were given an Academic Writing Course in the second semester of the 2015-2016 academic year, which lasted for a 16week period. There were a total of 150 Computer Science and Computer Technology majors in two sections: 75 students in each section. Students' writing tasks were broken down into manageable assignments every two week in developing a specific writing task within each 
assignment. In the first 12 weeks of the course, students had to do assignments on the given task as shown in figure 1. Each of the first six assignments was evaluated by the instructor over the week and the feedback was given in the following week, just before they submitted their next assignment. For each assignment, the instructor not only gave in-text feedback and overall comments on students' writing but also discussed common errors with the whole class and asked the students to revise their writings. Then, the students put forward their final assignment whereupon peer reviewing was engaged in the classroom. Each student reviewed 3 papers in a two- hour class and gave written feedback on peers' writing. Once the activity was finished, the students reviewed their returned papers with peer feedback. Finally, they revised their writing and put forward their final papers in the following week.

\section{The Nature of Assigned Writing Tasks}

The first five assignments were just pieces of writing tasks which are related with one another as shown in figure 1. In the first assignment, the students had to write only the research question statement. In the second assignment, they had to give a claim or thesis statement that is related with the research question presented in the first assignment. In the third assignment, reasons for the claim or thesis statement was given. In the fourth and fifth assignments, outline of the whole paper and introduction were assigned receptively. First draft assignment, which is the whole essay in the given format and outline had to be submitted as the sixth assignment. The students are required to complete an essay of $3000-3500$ words as the main writing task of the Writing Course wherein instructor feedback and peer feedback was given. The format of the paper (font size, margin, line spacing) and the main contents (Introduction, Body, Conclusion, Reference list) were described in advance.

\section{Procedure of Assignments}

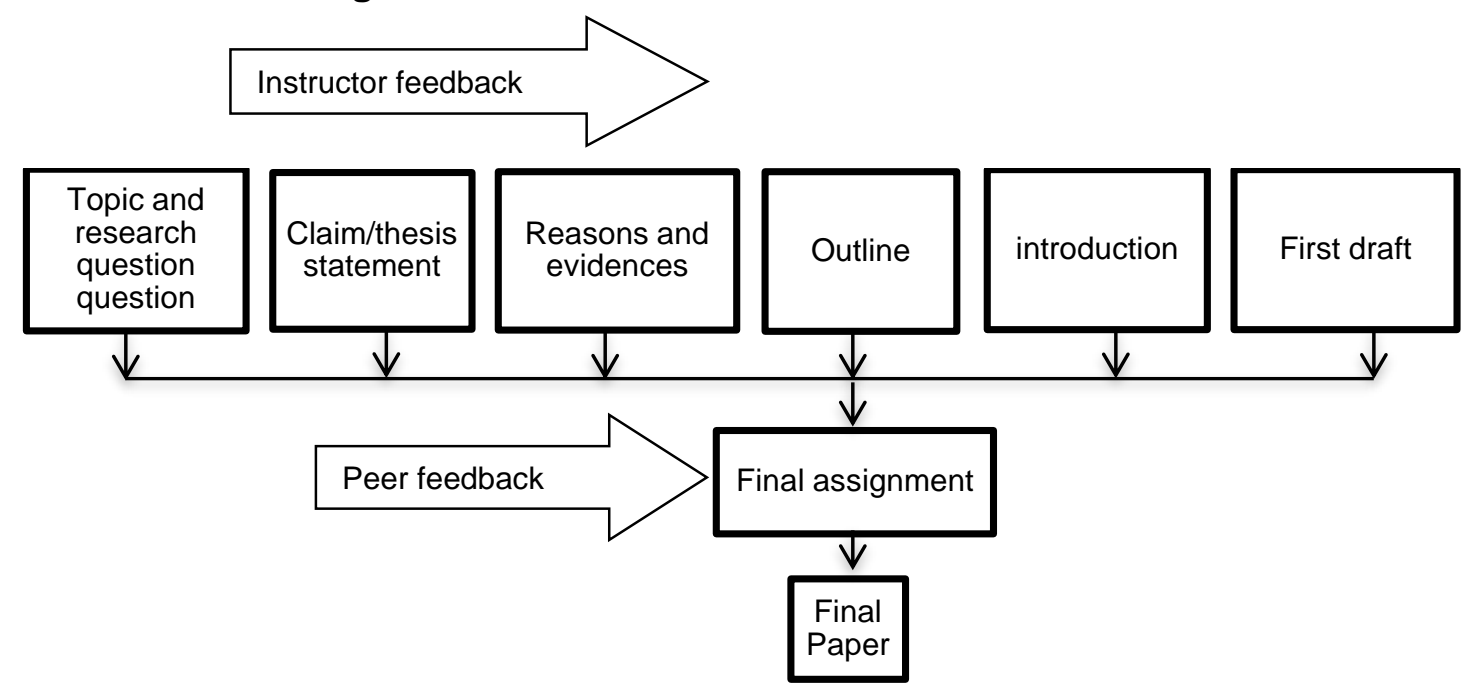

Fig 1.The procedure of assignments on categories showing where instructor feedback and peer feedback is given 


\section{Guided Written Feedback}

In the peer-reviewing process, the students were guided how to write positive comments not only in-text but on a separate sheet of paper which was attached to the final assignment. Instructions was provided on the use of written feedback, in general of 4 types as the way the instructor did on their first drafts; Error identification, Error correction and Descriptive comment and Critical comment.

Regarding the Error identification, students were instructed to circle the misspelling word, cross out of an unnecessary word/phrase/morpheme, underline the incorrect tenses and structures, and point the inappropriate expressions by arrows. Error identification is a kind of indirect corrective feedback that indicates in some way an error has been made. (Ferris \& Roberts, 2001)

For the Error correction, they were told to cross out the word or phrase and write a correct one nearby. It is a kind of Direct corrective feedback which may be defi ned as the provision of the correct linguistic form or structure above or near the linguistic error (Bitchener et al., 2005). It may include the crossing out of an unnecessary word/phrase/morpheme, the insertion of a missing word/phrase/morpheme, or the provision of the correct form or structure.

With respect to Content Comment, there are two types: descriptive comments and critical comments. Descriptive comments are imperatives for giving specific instructions to the writer. (e.g. Check your paper format, Rewrite your thesis statement, Check your citation). For the critical comments, students were asked to write positive comments on various parts of the essay both in-text and in a separate sheet of paper as overall comments. They were also asked to comment on the introduction and coherence and to detect grammar, punctuation and spelling errors. The purpose of encouraging the use of positive feedback is to reduce offence among students and to practice the use of more positive and objective language expressions. They were encouraged to mention impersonal nouns instead of first person pronouns. Some sentences from the list of peer review guidelines by Liu and Hansen (2002) were also used to engage the students with more appropriate language expressions.

\section{Guided language expressions for giving feedback}

\begin{tabular}{|l|l|}
\hline \multicolumn{1}{|c|}{ Personal } & \multicolumn{1}{c|}{ Impersonal } \\
\hline You are weak in grammar. & $\begin{array}{l}\text { This paper is grammatically weak/ Grammatical aspect needs } \\
\text { improvement. } \\
\text { Direction is required in introduction. } \\
\text { You don't write a thesis statement. }\end{array}$ \\
Your sentences are not coherent. & Thesis statement is missing in this paper. \\
Your citations are incorrect. & Citation must be accurate. \\
Your paper format is wrong. & Check the paper format which needs a slight changes. \\
Your references are incomplete. & Reference list needs to be rewritten. \\
\hline
\end{tabular}




\section{Data Analysis}

To determine the effect of instructor feedback, the number of feedback types and categories on 20 randomly selected first draft assignments were counted. Then the number feedback implementation on these selected papers were analyzed. Similarly, after 2 hour peer reviewing activity on final assignments, the same 20 papers were reviewed to investigate the number of peer feedback on the given categories and peer feedback implementation. Quantitative data of Instructor feedback effect was compared with the data on peer feedback implementation. In counting peer feedback numbers, redundant feedback of different types on the same purpose is not considered. Then any slight changes to the peer feedback given words or phrases are counted as feedback implementation regardless of the validity of the implementation.

\section{Findings}

\section{In-Text and Overall Feedback}

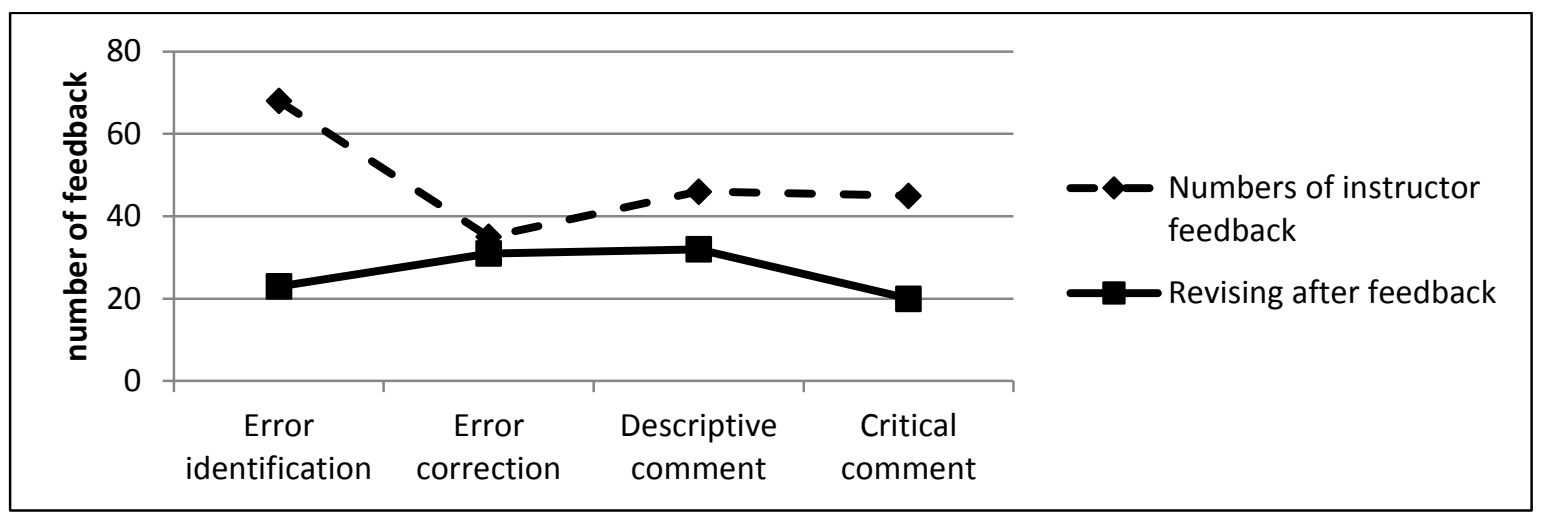

Figure 2. Total number of feedback comments given to 20 students' first drafts by the instructor and the number of feedback comments the students incorporated into their writing It was found that only 20 out of 70 error identifications given by the instructor were implemented whereas 31 out of 35 error corrections on grammatical structure, punctuation and vocabulary use were revised by using instructor feedback. Most of the errors identified by the instructor are citations, quotations, vocabulary, coherence and structure. It was discovered that students implemented most of the underlined or circled vocabularies and structural expressions, very few identifications on quotations and citations were revised.

However, students' revision rate on error correction by the instructor was significantly higher. The instructor gave the direct corrective feedback to some of the errors found in text. Some tense errors, vocabulary errors, propositions, articles and punctuations are crossed out and the correct linguistic forms or structure was provided. In that type of written feedback, it was found that the students revised 31 out of 35 error corrections in their final assignments.

Descriptive comments of the instructor are related with format, citation, reference, grammar and structural expressions and punctuation. Some of which include "check your format", "change your font size", "put citation here", "it must be in passive form", "check your punctuation", and "citation and references are not matched". Some of the instructor's critical comments are "thesis statement is missing", "main points should be restated in conclusion", 
"more references should be used", "organization of the paper is weak", "it should be more coherence" and "there should be background information in the introduction".

The number of descriptive comments and critical comments on 20 students' first drafts were nearly 50 on each comment type. However, it was discovered that only 30 and 20 comments on each category were revised as shown in Figure 2. On the students' final assignments, there was an evidence of highest revision work for punctuation, format and citation based on the instructor's descriptive and critical comments. Regarding the instructor's critical comments related with coherence and organization, students repeated the same writing on their following assignments.

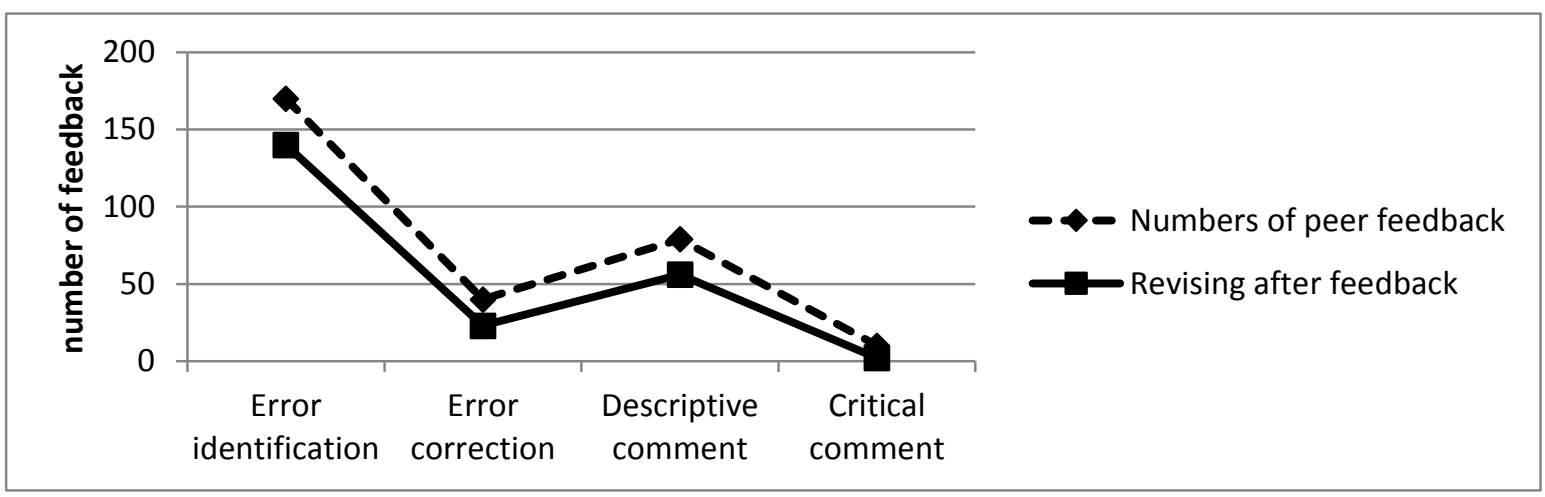

Figure 3. Total number of feedback comments on 20 final assignments by 3 student reviewers and number of feedback comments the students incorporated into their writing

Peer feedback comments on the same 20 final assignments were counted and final papers were reviewed to study the revision work. It was discovered that 140 out of 170 error identifications on 20 selected papers were revised using peer feedback. But just over $50 \%$ of the error corrections ( 23 corrections out of 40 ) by peers were incorporated into revision work. Then, 56 and 2 for descriptive comments and critical comments of peers were implemented although comment numbers were 79 and 10 respectively.

Although peers' descriptive comments are more or less similar with the instructor, 8 out of 10 comments are about the overall impression of the paper such as "this paper is interesting", "this paper is weak in organization". The only two comments that was implemented in the revision is "thesis statement should be rewritten" and "thesis statement is not clear and it should be rewritten". Unlike the instructor, it was found that students gave significantly higher numbers of error identification feedback than error corrections. Then, critical comment numbers by peers was comparatively fewer than the instructor's. 
Table 1

A comparison of implementation rate of instructor and peer feedback

\begin{tabular}{|l|l|l|}
\hline Types & Instructor feedback effect & Peer feedback effect \\
\hline Error identification & $33.82 \%$ & $82.35 \%$ \\
\hline Error correction & $88.57 \% \%$ & $57.5 \%$ \\
\hline Descriptive comment & $69.56 \%$ & $70.88 \%$ \\
\hline Critical comment & $44.44 \%$ & $20 \%$ \\
\hline
\end{tabular}

\section{Table 2}

A comparison of the number of instructor and peer feedback given and revision work and by types and categories

\begin{tabular}{|c|c|c|c|c|c|}
\hline Types & Categories & $\begin{array}{c}\text { Total } \\
\text { Instructor } \\
\text { feedback } \\
\text { given }(\mathrm{N}=20)\end{array}$ & $\begin{array}{l}\text { Total No of } \\
\text { revision }\end{array}$ & $\begin{array}{c}\text { Total Peer } \\
\text { feedback } \\
\text { Given } \\
(\mathrm{N}=20) \\
\end{array}$ & $\begin{array}{l}\text { Total No of } \\
\text { revision }\end{array}$ \\
\hline \multirow{5}{*}{$\begin{array}{l}\text { Error } \\
\text { identification }\end{array}$} & Grammar & 16 & 9 & 45 & 33 \\
\hline & Vocabulary & 7 & 3 & 24 & 17 \\
\hline & Font and line-spacing & 16 & 5 & 37 & 35 \\
\hline & Citation & 8 & 2 & 41 & 37 \\
\hline & Punctuation & 21 & 4 & 23 & 18 \\
\hline \multirow[t]{4}{*}{ Error correction } & Grammar & 12 & 11 & 16 & 10 \\
\hline & Vocabulary & 10 & 10 & 12 & 4 \\
\hline & Structures & 5 & 5 & 5 & 3 \\
\hline & Punctuation & 8 & 6 & 7 & 6 \\
\hline \multirow{4}{*}{$\begin{array}{l}\text { Descriptive } \\
\text { comment }\end{array}$} & Format & 10 & 5 & 25 & 18 \\
\hline & $\begin{array}{l}\text { Citation and } \\
\text { References }\end{array}$ & 10 & 4 & 24 & 16 \\
\hline & Introduction & 13 & 12 & 18 & 15 \\
\hline & Conclusion & 13 & 10 & 12 & 7 \\
\hline \multirow[t]{4}{*}{ Critical comment } & Introduction & 14 & 8 & 3 & 2 \\
\hline & Conclusion & 10 & 7 & 2 & - \\
\hline & Organization & 12 & 2 & 2 & - \\
\hline & $\begin{array}{l}\text { Reasons and } \\
\text { evidences }\end{array}$ & 9 & 3 & 3 & - \\
\hline
\end{tabular}

Table 1 shows a comparison of the effect of instructor and peer feedback. The rate of students' revising their writing using error identifications by peers is nearly $50 \%$ higher than the instructor feedback implementation. Regarding the descriptive comment implementation, instructor feedback and peer feedback effect are nearly equal, whereas the students incorporated the instructor's feedback into their writing 30\% and over $20 \%$ higher on error correction and critical comment than the revision percentage after peer feedback of these types. Then a comparison of the number of peer and instructor feedback given and implementation by types and categories is shown in table 2 .

\section{Discussion}

The first finding from this study was that the total number of feedback comments on error identifications that were incorporated into writing after instructor feedback was less than that of peer-feedback. This provides a response to the first research question. It can thus be raised as to why some students did not revise their writing after the instructor's feedback on error 
identifications. Certainly timing was an important factor. In this study, the instructor gave feedback to peers a week after their assignment submission, whereas peer feedback was shown shortly after the writing activity. Thus, this present study adds to the contention of Ngar-Fun \& Carless (2006) that the timeliness of peer feedback benefits learners, especially because it results in higher rate of error identification as opposed to teacher feedback. However, another explanation for this phenomenon is that this could have been because students had a lack of understanding of the instructor's feedback, which highlights only common errors in their writing. They might have only understood the correct use of citation, referencing and format only when they were exposed to good and bad examples of others' work.

Despite the significant effect of peer-feedback on error identifications, only a few students used descriptive comments and critical comments given by peers, which was less than the effect of instructor feedback. If the students' peer feedback implementation is to be interpreted by the findings of Nelson \& Schunn (2009), it can be assumed that the types of peer feedback that the students understood most were error identifications and error corrections rather than content comments. It could have been the case that students suspected the authority or competence of peers to deliver descriptive or critical comments, while placing high value and authoritative role of the comments provided by the instructor. This is in line with previous studies such as Tsui \& Ng (2000) and Nelson \& Murphy (1993) that those incorporating a low percentage of peer comments perceived the teacher as the sole source of authority, demonstrating low confidence in their peers who were non-native speakers of English and might not be rendered authoritative to provide quality comments.

But the issue of linguistic authority seems to be hierarchical in this study. Even among students themselves, it appears that there is a hierarchy as to which students are considered more proficient than others, hence being more authoritative. This is evidenced by the fact that some students were asking for more competent students' papers for the 2nd and 3rd time reviewing during the activity as they were not impressed with the first paper they had reviewed. Most of the second- and third- time reviewers of the same paper gave feedback on different categories that were not addressed by the first reviewer. This indicates that the subsequent reviewers had a chance to learn the previous reviewer' feedback and tried to give different feedback. It suggests that the learning process in reviewing others' writing plays a more significant role than getting feedback, which may be in lined with the findings of Lundstrom \& Baker (2009) in which the students learned better in reviewing others' work than receiving feedback on their own work. In this present study, it seems that most students realized the correct citations and referencing format only after experiences through peer reviewing. Therefore, the learning process of the students should also be investigated more: whether they learned better through reviewing the peer-feedback they obtained or seeing the common errors by reviewing others' work. In this case, the findings of the study are parallel to Jacobs et al.'s (1998) contention that peer feedback should be used as a process approach that guides students in their learning rather than as an end in itself.

The second finding answers the second research question. The second finding in this study was generally consistent with the study of Min (2006) on the kinds of feedback student writers 
incorporated into their text after given peer reviewing training. Error identification is the feedback type which most students incorporated into their revision work. This indicates that the present study demonstrates parallelism with previous studies such as Bitchener et al. (2005) in which indirect corrective feedback has a greater effect than direct feedback. The instructor also gains insight onto the students' critical skills and language skills by reviewing the peer feedback categories.

Although it was recommended to engage students with out-of-class paper reviewing by Crowe, Silva \& Ceresola (2015), the common learning style of Myanmar students is heavily reliant on teacher's instructions in the classroom. This was proven by the way the students in this study participated actively in this 2- hour intensive in-class peer reviewing activity. Attempts to replicate the strategies used in this study in other contexts in the ASEAN region that aims to enhance students' active participation in L2 writing classes must bear in mind this contextual factor.

In this regard, it might be necessary to even out the authoritative mode through the employment of several cycles of peer feedback of the same type. On the one hand, ensuring that learners have the opportunities to access feedback from different reviewers provides them with opportunities to access different cycles of feedback that is conducive to L2 writing (Wigglesworth \& Storch, 2009). On the other hand, it also allows for the provision of finetuned and targeted written corrective feedback that can potentially increase student engagement (Han \& Hyland, 2015). Moreover, implementing the combination of full, explicit and written teacher and peer feedback along with various cycles of feedback could also lead to increased accuracy performance. Employing error correction through various combined strategies of teacher and peer feedback could prove judicious and effective to improved L2 writing performance rather than sole reliance on teacher feedback (Bitchener et al., 2005; Gielen et al., 2010; Van Gennip et al., 2010).

\section{Limitation of the Research}

This study is limited by the weaknesses. First, the number of the students' revision work on their paper was counted by the evidences of some linguistic changes in terms of structure, format, punctuation, vocabulary and spelling on their returned paper. It may also be not because of the peer feedback effect but because of their skills development later. Second, the data collected from 20 randomly-selected papers has yielded a sampling of the effect of peer feedback in the writing course. There may be slight variations in peer feedback implementation on specific parts of the writing process if all students' papers are analyzed. Then, this study will be viewed within the context of Myanmar language education to gain insights into the reasons behind teaching writing in a large class.

\section{Conclusion}

Peer reviewing and giving peer feedback as an intensive in-class activity was done to investigate whether it is an effective way in teaching writing skills in a large EFL class in this research. This research is aimed to help EFL faculty members of other Universities in Myanmar and ASEAN region which have a similar context understand that peer feedback process can effectively be used in teaching writing skills. The study undertaken contributes 
towards the good outcomes of the students' overall learning process to some extent and development of a positive attitude towards peers' feedback in their revision work. It can be said that the majority of students feel confident to give feedback on peers' language skills and there was evidences of using peers' indirect corrective feedback in the revision work although limited number of critical comments were discovered. In conclusion, peer reviewing and giving peer feedback is an effective learning process which should be used in other large EFL classes of other Universities in similar situation and in other subjects as well. In this in-class previewing and giving peer feedback activity, each paper was given feedback by three peers. It was found that $2^{\text {nd }}$ and $3^{\text {rd }}$ reviewers also had a chance to learn the former reviewer's peer feedback. Therefore, it is required to study the effect of the different peer feedback on the performance of the revision work and the influence of the former peer feedback on the performance of subsequent peer reviewers as a further study. 


\section{Author Note}

Yi Yi Mon

Department of Languages

The University of Computer Studies, Mandalay

Myanmar

yeewise@gmail.com

Subhan Zein

School of Education

The University of Queensland, Australia

m.zein@uq.edu.auss

ORCID ID: 0000-0003-3787-3211

This study is based on the data from the students' assignments, peer reviewed papers and questionnaire responses to the Academic Writing Course of the fourth year students in the University of Computer Studies, Mandalay in 2016 academic year.

Contact information:

Yi Yi Mon

The University of Computer Studies, Mandalay

Dahuttaw, Patheingyi township, Mandalay Region, Myanmar

Phone: +9596502215

E-mail: ucsmuser@gmail.com

Institution website :www.ucsm.edu.mm 


\section{References}

Bitchener, J., Young, S., \& Cameron, D. (2005). The effect of different types of corrective feedback on ESL student writing. Journal of Second Language Writing, 14(3), 191-205. doi: https://doi.org/10.1016/j.jslw.2005.08.001

Crowe, J. A., Silva, T., \& Ceresola, R. (2015). The Effect of Peer Review on Student Learning Outcomes in a Research Methods Course. Teaching Sociology, 43(3), 201-213. https://doi.org/10.1177/0092055X15578033

Cho, K., Schunn, C. D., \& Wilson, R. W. (2006). Validity and reliability of scaffolded peer assessment of writing from instructor and student perspectives. Journal of Educational Psychology, 98(4), 891. http://psycnet.apa.org/doi/10.1037/0022-0663.98.4.891

Ferris, D., \& Roberts, B. (2001). Error feedback in L2 writing classes: How explicit does it need to be? .Journal of Second Language Writing, 103), 161-184. https://doi.org/10.1016/S1060-3743(01)00039-X

Gielen, S., Tops, L., Dochy, F., Onghena, P., \& Smeets, S. (2010). A comparative study of peer and teacher feedback and of various peer feedback forms in a secondary school writing curriculum. British Educational Research Journal, 36(1), 143-162. DOI: https://doi.org/10.1080/01411920902894070

Han, Y., \& Hyland, F. (2015). Exploring learner engagement with written corrective feedback in a Chinese tertiary EFL classroom. Journal of Second Language Writing, 30, 31-44. http://dx.doi.org/10.1016/j.jslw.2015.08.002

Hu, G. (2005). Using peer review with Chinese ESL student writers. Language Teaching Research, 9(3), 321-342. 10.1191/1362168805Ir169oa https://www.researchgate.net/publication/234119408

Jacobs, G. M., Curtis, A., Braine, G., \& Huang, S. Y. (1998). Feedback on student writing: Taking the middle path. Journal of Second Language Writing, 73), 307-317. https://doi.org/10.1016/S1060-3743(98)90019-4

Lam, R. (2010). A peer review training workshop: Coaching students to give and evaluate peer feedback. TESL Canada Journal, 27(2), 114-127 https://doi.org/10.18806/tesl.v27i2.1052

Landry, A., Jacobs, S., \& Newton, G. (2014). Effective use of peer assessment in a graduate level writing assignment: A case study. International Journal of Higher Education, 4(1), 38. https://doi.org/10.5430/ijhe.v4n1p38

Liou, H. C., \& Peng, Z. Y. (2009). Training effects on computer-mediated peer review. System, 373), 514-525. https://doi.org/10.1016/j.system.2009.01.005

Liu, J., \& Hansen, J. G. (2002). Peer response in second language writing classrooms. Ann Arbor: University of Michigan Press.

Lundstrom, K., \& Baker, W. (2009). To give is better than to receive: The benefits of peer review to the reviewer's own writing. Journal of Second Language Writing, 18(1), 3043. https://doi.org/10.1016/j.jslw.2008.06.002

Min, H. T. (2005). Training students to become successful peer reviewers. System, 33(2), 293308. https://doi.org/10.1016/j.system.2004.11.003

Min, H. T. (2006). The effects of trained peer review on EFL students' revision types and writing quality. Journal of Second Language Writing, 15(2), 118-141. https://doi.org/10.1016/j.jslw.2006.01.003 
Min, H. T. (2008). Reviewer stances and writer perceptions in EFL peer review training. English for Specific Purposes, 273), 285-305. http://dx.doi.org/10.1016/j.esp.2008.02.002.

Min, H. T. (2016). Effect of teacher modeling and feedback on EFL students' peer review skills in peer review training. Journal of Second Language Writing, 31, 43-57. http://dx.doi.org/10.1016/j.jslw.2016.01.004

Nelson, G., \& Murphy, J. (1993). Peer response groups: Do L2 writers use peer comments in revising their drafts? TESOL Quarterly, 271), 135-142. DOI: 10.2307/3586965

Nelson, M. M., \& Schunn, C. D. (2009). The nature of feedback: How different types of peer feedback affect writing performance. Instructional Science, 374), 375-401. 37: 375. https://doi.org/10.1007/s11251-008-9053-x

Ngar-Fun, L., \& Carless, D. (2006). Peer feedback: The learning element of peer assessment. Teaching in Higher Education, 11(3) 279290. https://doi.org/10.1080/13562510600680582

Peterson, S. (2003). Peer response and students' revisions of their narrative writing. L1 Educational Studies in Language and Literature, 3(3), 239-272. https://doi.org/10.1023/B:ESLL.0000003605.45224.b5

Richer. D. L., ( 1992) . The effects of two feedback systems on first year college students' writing proficiency. Available at: https://elibrary.ru/item.asp?id=5775194

Rust C, Price M \& O'Donovan B (2003) Improving students' learning by developing their understanding of assessment criteria and processes. Assessment \& Evaluation in Higher Education 28(2): 147-64. https://doi.org/10.1080/02602930301671

Storch, N. (2004). Using activity theory to explain differences in patterns of dyadic interactions in an ESL class. Canadian Modern Language Review, 6044), 457-480. https://doi.org/10.3138/cmlr.60.4.457

Topping. K. J. (1998). Peer assessment between students inn colleges and universities. Review of Educational Research. 68(3), 249-276,

Truscott, J. (1996). The case against grammar correction in L2 writing classes. Language Learning, 46(2), 327-369. DOI: https://doi.org/10.1111/j.1467-1770.1996.tb01238.x

Truscott, J. (1999). The case for "The case against grammar correction in L2 writing classes": A response to Ferris. Journal of Second Language Writing, 8(2), 111-122. https://doi.org/10.1016/S1060-3743(99)80110-6

Tsui, A. B. M., \& Ng, M. (2000). Do secondary L2 writers benefit from peer comments? Journal of Second Language Writing, 9, 147-170. http://dx.doi.org/ 10.1016/S10603743(00)00022-9.

Van Gennip, N. A., Segers, M. S., \& Tillema, H. H. (2010). Peer assessment as a collaborative learning activity: The role of interpersonal variables and conceptions. Learning and Instruction, 2044), 280-290. https://doi.org/10.1016/j.learninstruc.2009.08.010

Wigglesworth, G., \& Storch, N. (2009). Pair versus individual writing: Effects on fluency, complexity and accuracy. Language Testing, 26(3), 445-466. doi/abs/ https://doi.org/10.1177/0265532209104670

Yang, M., Badger, R., \& Yu, Z. (2006). A comparative study of peer and teacher feedback in a Chinese EFL writing class. Journal of Second Language Writing, 15(3), 179-200. https://doi.org/10.1016/j.jslw.2006.09.004 
Yang, Y.-F., \& Meng, W.-T. (2013). The effects of online feedback on students' text revision. Language Learning \& Technology, 17(2), 220-238. Retrieved from http://lt.msu.edu/issues/june2013/yangmeng.pdf

Zhang, S. (1995). Reexamining the affective advantage of peer feedback in the ESL writ- ing class. Journal of Second Language Writing 4, 209-222. https://doi.org/10.1016/10603743(95)90010-1

Zhang, S. (1999). Thoughts on some recent evidence concerning the affective advantage of peer feedback. Journal of Second Language Writing, 8(3), 321-326.

https://doi.org/10.1016/S1060-3743 (99)80119-2 